\title{
A DOSE RESPONSE STUDY FOR THE ANTI ARTHRITIC EFFECT OF RESVERATROL IN A MODEL OF ADJUVANT ARTHRITIS IN RATS \\ BY
}

\author{
Hend M. Rizk ${ }^{\mathrm{a}}$, Reem N. El-Naga ${ }^{\mathrm{a}}$, Ebtehal El-Demerdash $^{\mathrm{a}}$
}

FROM

a: Department of Pharmacology \& Toxicology, Faculty of Pharmacy, Ain Shams University, Cairo, Egypt

\begin{abstract}
The aim of this study was to investigate the effects of resveratrol (Res) on the clinical symptoms of rheumatoid arthritis in rats with adjuvant arthritis (AA). An AA model was established by injection of complete Freund's adjuvant (CFA). Ankle diameter, paw volume, arthritic index, gait score as well as paw histopathological examination were assessed to determine the anti-arthritic effect of Res. Resveratrol, at dose $50 \mathrm{mg} / \mathrm{kg}$, was able to significantly alleviate rheumatoid related paw swelling and ankle diameter and decrease both arthritic and gait scores. Besides, a significant reduction of inflammatory cell infiltration in the ankle joint tissue was shown by histopathological examination. These findings confirm the anti-rheumatic activity of Res which can be correlated to its anti-inflammatory activity.
\end{abstract}

Keywords: Resveratrol; Complete Freund's Adjuvant; Arthritis; Rats.

\section{INTRODUCTION}

Rheumatoid arthritis (RA) is a chronic autoimmune disease characterized by swelling of joints, synovitis and degeneration (Trentham et al. 1980) causing progressive damage to the musculoskeletal system, which contributes to the loss of physical function and quality of life (Müller-Ladner et al. 2005; Plasqui 2008). RA prevalence rates in developed populations are approximately $0.5 \%$ to $1 \%$ of the adult population. The standardized mortality ratios vary from 1.28 to 2.98. Epidemiological studies have consistently demonstrated increased mortality in patients with RA compared with the expected rates in the general population (Gabriel and Michaud 2009).

Etiology of RA is unknown. Although genetic factors play an essential role, they are not sufficient to explain the triggering of the immune insult. The dominant feature in RA is inflammation, primarily in synovium, which is accompanied by synovial hyperplasia. There is also increased number of both type synoviocytes in addition to immune and inflammatory cells infiltration particularly macrophages, B- and Tlymphocytes, plasma cells and dendritic cells. Cytokines level increases and play a central role in the propagation of synovial inflammation. The persistence of the chronic inflammatory response is in conjunction with ongoing joint destruction (MorovićVergles 2003).

At present, the main treatment options for RA range from nonsteroidal antiinflammatory drugs (NSAIDs) to disease-modifying anti-rheumatic drugs (DMARDs) 
such as methotrexate as the cornerstone of therapy. While biological DMARDs such as antitumor necrosis factor (TNF), interleukin (IL)-1, and IL-6 receptor antagonists are usually considered only when patients fail to respond to conventional DMARDs. However, the lack of reliable treatment for early RA is a troublesome problem for doctors because most NSAIDs and DMARDs treatments cause severe side effects including stomach ulcers and bleeding in the case of NSAIDs and high blood pressure, osteoporosis, weight gain, and infections in the case of DMARDs (Singh et al. 2012; Vivar and Van Vollenhoven 2014).

In this context, it is necessary to develop effective anti-rheumatic therapies with fewer side-effects. Natural plant extracts can be an alternative source of bioactive agents with anti-rheumatic potential. Resveratrol (RSV; trans-3,5,40-trihydroxystilbene) is a polyphenol widely present in a large number of plant species, some of which are components of the human diet, such as berries, peanuts, grapes and red wine (Park et al. 2012). Resveratrol has been reported to possess antioxidant, anti-inflammatory, anticancer, immunomodulatory and pro-apoptotic properties, all of which make it a highly interesting compound for the treatment of RA (Park et al. 2012).

Several studies have been conducted on the use of RSV in the treatment of RA. It was shown, in vitro, that RSV plays an anti-inflammatory role in RA synoviocytes through a reduction in the expression of cytokines and MMPs (Tian et al. 2013). Furthermore, it was found that Res has an anti-inflammatory effect on human synoviocytes by decreasing ROS production and nuclear factor-kB activation (Valcarcel-Ares et al. 2014). In vivo, it was found to reduce synovial inflammation and cartilage lesions in a monoarthritis model induced by repeated intra-articular injections of lipopolysaccharide (Elmali et al. 2007). Recently, it is shown that the intraperitoneal administration of RSV modulated murine CIA by inhibiting Th17 and B-cell function (Xuzhu et al. 2012) as well as gouty arthritis (Chen et al. 2016).

The present study was designed to examine the anti-arthritic effects of Res in an adjuvant arthritis model (AA) in rats. Rat adjuvant arthritis is an experimental model of polyarthritis that has been widely used for preclinical testing of numerous anti-arthritis agents that are either under preclinical or clinical investigation or are currently used as therapeutics in this disease (PEARSON 1956; Carlson et al. 1985; Benslay and Bendele 1991). The hallmarks of this model are reliable onset of robust polyarticular inflammation, marked bone resorption, and periosteal bone proliferation. Cartilage destruction occurs but is disproportionally mild in comparison to the inflammation and bone destruction that occur(Riveiro-Naveira et al. 2016) 


\section{MATERIALS AND METHODS:}

\subsection{Drugs and chemicals:}

Resveratrol was purchased from Shaanxi Huike Biotechnology Co. (Ltd, China). Complete Freund's adjuvant (CFA) and dimethylsulfoxide (DMSO) were purchased from Sigma-Aldrich Co. (USA). Complete Freund's adjuvant consists of a mixture of heat- killed Mycobacterium tuberculosis suspended in sterile mineral oil (1 mg/ml). All other chemicals and solvents were of highest grade and commercially available.

\subsection{Animals:}

Fifty male Wister rats weighing 150-200 g were obtained from Nile Co. for Pharmaceutical and Chemical Industries, Egypt. Rats were acclimatized to the new housing conditions of the research facility for one week. They were housed in an airconditioned atmosphere, at a temperature of $25^{\circ} \mathrm{C}$ with alternative 12 hour light and dark cycles. They were kept on a standard diet and water ad libitum. Standard diet pellets contained not less than $20 \%$ protein, $5 \%$ fiber, $3.5 \%$ fat, $6.5 \%$ ash and a vitamin mixture. The food was placed on the sawdust in the cage to be easily accessible by animals. The experimental protocol was approved by Ain Shams University Faculty of Pharmacy Ethical Committee for the use of animal subjects (permit \# PhD13).

\subsection{Experimental design:}

Animals were randomly allocated into 5 groups $(n=10)$ as follows: group 1 (control) was injected with saline, group 2 (non-treated arthritic rats), groups 3,4 , and 5 (arthritic rats treated with resveratrol in doses $12.5,25$, and $50 \mathrm{mg} / \mathrm{kg} / \mathrm{day}$ respectively) orally(Chen et al. 2013). Arthritis was induced in rats via subcutaneous injection of 0.1 $\mathrm{ml}$ CFA into the plantar surface of the left hind paw. Then, Another booster intradermal injection of $0.1 \mathrm{ml}$ was given into the root of the tail on the same and on the following day (Helyes et al. 2001). The treatment started on the day after the induction of arthritis, and continued for 21 days(Darwish et al. 2013). On day 21 after immunization, animals were sacrificed and left hind paws were excised and fixed in $10 \%$ buffered formalin for histopathological examination.

\subsection{Assessment of arthritis:}

The progression of CFA induced arthritis was evaluated on days $0,1,3,6,8,10$, 13, 15, 17 and 21 after adjuvant injection through the measurement of left hind paw volume, ankle diameter, arthritic score, and gait score.

\subsection{Hind paw swelling:}

the volume of left hind paw was measured with an electronic water plethysmometer (UGO BASILE, Italy) on days 14, 21, and 28 (Rovenský et al. 2009).

\subsection{Ankle diameter:}

left hind paw ankle diameter was determined by measuring the antero-posterior diameter, using vernier caliper which is accurate to $0.02 \mathrm{~mm}$ (Ramprasath et al., 2006)

\subsection{Arthritic scoring:}

left hind paws were examined and graded for severity of erythema and swelling using a 5-point scale: $0=$ no signs of inflammation, $1=$ swelling and erythema of the 
digit, $2=$ moderate swelling and erythema, $3=$ severe swelling and erythema of the limb and 4 =severe swelling, erythema, gross deformity and disability to use the limb.(Kim et al. 2008)

\subsection{Gait scoring:}

it was used to assess the arthritis pain using the following scale from 0 to $3: 0=$ normal gait, $1=$ gait with slight lameness, $2=$ lameness with weight bearing on toes only, $3=$ non weight bearing animals(Bush et al., 2001).

\subsection{Histopathology of hind paw:}

Paws from different groups were excised, fixed in $10 \%$ formalin, decalcified in formic acid, embedded in paraffin blocks from which 5 micron-thick sections were obtained. Sections were stained with hematoxylin and eosin dye, and then evaluated under light microscope(Ishikawa et al. 2009).

\subsection{Statistical analysis:}

To analyze two sets of data, unpaired Student's t-test was used. To analyze more than two sets of data, one way analysis of variance (ANOVA) was used followed by Tukey-Kramer or Dunnett's test for multiple comparisons as appropriate. To analyze non-parametric data, Kruskal-Wallis test was used followed by Dunn's test for multiple comparisons. Analysis of data and presentation of graphs were performed using GraphPad Prism software version 5 (ISIß software, USA). Statistical significance was acceptable to a level of probability $<0.05$.

\section{RESULTS:}

\subsection{Anti-arthritic effects}

Twenty four hours after the injection of CFA, all of arthritic rats, whether treated or non-treated, developed significant arthritis with abnormal gait as compared to the normal control group manifested as significant increase in all arthritic parameters. Resveratrol treatment with dose $50 \mathrm{mg} / \mathrm{kg}$ significantly $(\mathrm{p}<0.001)$ reversed the changes in both ankle diameter and paw volume as compared to arthritic non-treated rats. On the other hand, treatment with resveratrol at doses 12.5 , and $25 \mathrm{mg} / \mathrm{kg}$ did not show any significant change ( $>>0.05)$ from the arthritic non treated group, (Fig.1). Concerning the arthritic index, and the gait scoring the treatment of arthritic rats with resveratrol at a dose $50 \mathrm{mg} / \mathrm{kg}$ showed a significant improvement in both parameters $(\mathrm{p}<0.05)$ at the end of the experiment as compared to arthritic non treated rats. While the other two doses of resveratrol $(12.5$, and $25 \mathrm{mg} / \mathrm{kg}$ ) did not show any significant improvement in the arthritic severity score or gait score compared to the arthritic non treated group, (Fig.2). Regarding the contralateral paw, no significant changes in neither volume nor ankle diameter were observed throughout the experiment in all groups.

\subsection{Histopathological examination of rats left hind paw}

Compared to the control group, the arthritic rats showed massive number of inflammatory cells infiltration in the dermal tissue, subcutaneous tissue and musculature and extended to the periarticular tissue. These effects were significantly alleviated in the group receiving resveratrol at dose $50 \mathrm{mg} / \mathrm{kg}$ where the inflammatory cells infiltration was only localized in the subcutaneous tissue. Whereas the paws from the other two groups $(12.5$, and $25 \mathrm{mg} / \mathrm{kg}$ ) showed massive inflammatory cells infiltration in the 
subcutaneous tissue, musculature, and periostium as well as the tendon. There were fibrosis and inflammatory cells infiltration in the synovial membrane.(Fig.3, \& Table 1).

\section{DISCUSSION:}

Rheumatoid arthritis is a chronic, systemic inflammatory disease affecting approximately $1 \%$ of people worldwide (Kvien 2004). It is characterized by the persistent inflammatory synovitis, predominantly affecting the peripheral joints (Cojocaru et al. 2010). Most patients with the disease require continuous treatment to retard or stop progression and to control disease flares (Kvien 2004).

Adjuvant arthritis is an induced form of subchronic arthritis. It is most easily induced with a mixture of paraffin oils, mannide monooleate, and heat-killed mycobacteria, known as CFA.(Tuncel et al. 2016) The disease is a $T$ cell-mediated autoimmune arthritis that is frequently used to study immunological aspects of RA and other arthritic or inflammatory diseases in humans. Furthermore, it is used as a model for developing and testing anti-inflammatory drugs. Moreover, the model resembles spontaneous arthritic diseases in humans.(Van Eden et al., 2001) Although the etiology of AA remains unclear, a major immunogen in AA has been shown to be an HSP65derived peptide from mycobacteria(Van Eden et al. 1988) that triggers an autoreactive $T$ cell response against proteins in the joints (Van Eden et al. 1989).

The present study aimed to examine and compare the therapeutic effects of Res in three different doses on AA in rats. In the current study, the administration of Res at dose $50 \mathrm{mg} / \mathrm{kg}$ following immunization of rats with CFA markedly alleviated the swelling of the immunized hind paw. Histopathological examination of immunized hind paws showed that Res, in the previously mentioned dose, significantly reduced inflammatory cells infiltration in the muscular and periosteal tissue, though inflammatory cells were still found in the subcutaneous tissue. Due to the similarities in pathological features between AA and RA, these results indicate that Res may be effective in treating clinical RA (Asquith et al. 2009).

In accordance with these findings, Res showed anti-inflammatory activities. Several studies suggested that Res has a potential in vitro anti-inflammatory, anticatabolic, anti-apoptotic and anti-oxidative properties in various articular cell types, including chondrocytes and synoviocytes(Leong et al. 2013), along with its immunomodulation properties on $T$ and $B$ lymphocytes. (Gao et al. 2001) In preclinical models of osteoarthritis and rheumatoid arthritis, Res has shown joint protective effects, mainly mediated by decreased production of pro-inflammatory and pro-degradative soluble factors, and modulation of cellular and humoral responses. (Chen et al. 2014) Here in this study we studied the effect of different doses of resveratrol on the clinical symptoms of arthritis as the ankle diameter and paw swelling.

The present study revealed the therapeutic action of Res in AA rats was associated with its ability to alleviate the paw and ankle swelling, as well as improvement of arthritic index score and gait score resulting in improvement of paw joint mobility and the possible mechanism may be associated with reduction of inflammatory cytokines. The pharmacological effects of Res strongly suggest its potential therapeutic role for chronic RA. 
FIGURES \& TABLES

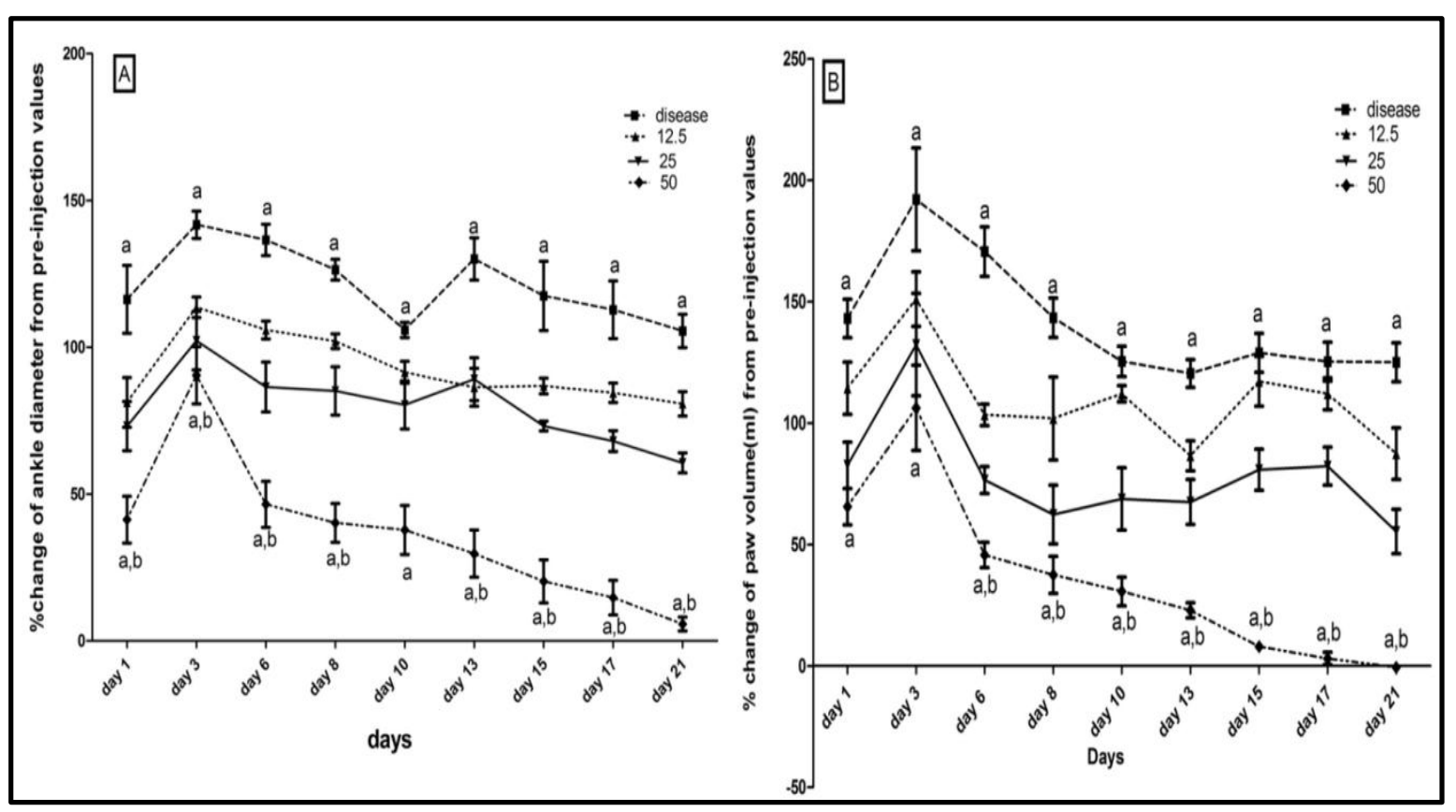

Figure 1. Effect of resveratrol on ankle diameter and paw volume.

Panel A: percentage change in ankle diameter, panel B: paw volume changes from preinjection values in adjuvant induced arthritic rats over a period of 21 days. Data are represented as mean $\pm \mathrm{SD}$. a or b: significantly different from the corresponding control or Arth group, respectively at P,0.05 using two way ANOVA followed by Bonferroni multiple comparison test,

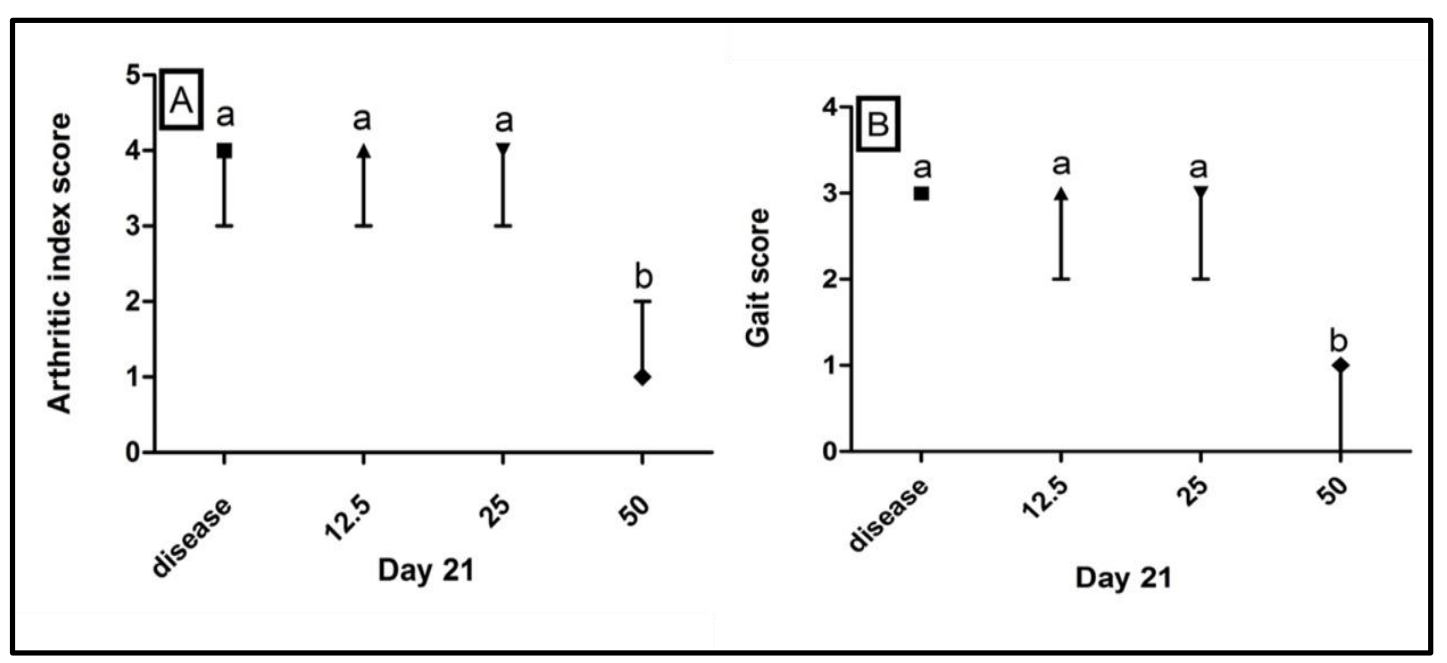

Figure 2. Effect of resveratrol on arthritic index and gait score. 
Panel A: arthritic index score and panel B: gait score on day 21 in adjuvant induced arthritis. Data are represented as medians and interquartile ranges $(n=10)$. a or $b$ : significantly different from the corresponding control or Arth group, respectively at P,0.05 using Kruskal-Wallis test followed by Dunn's Multiple Comparison Test.

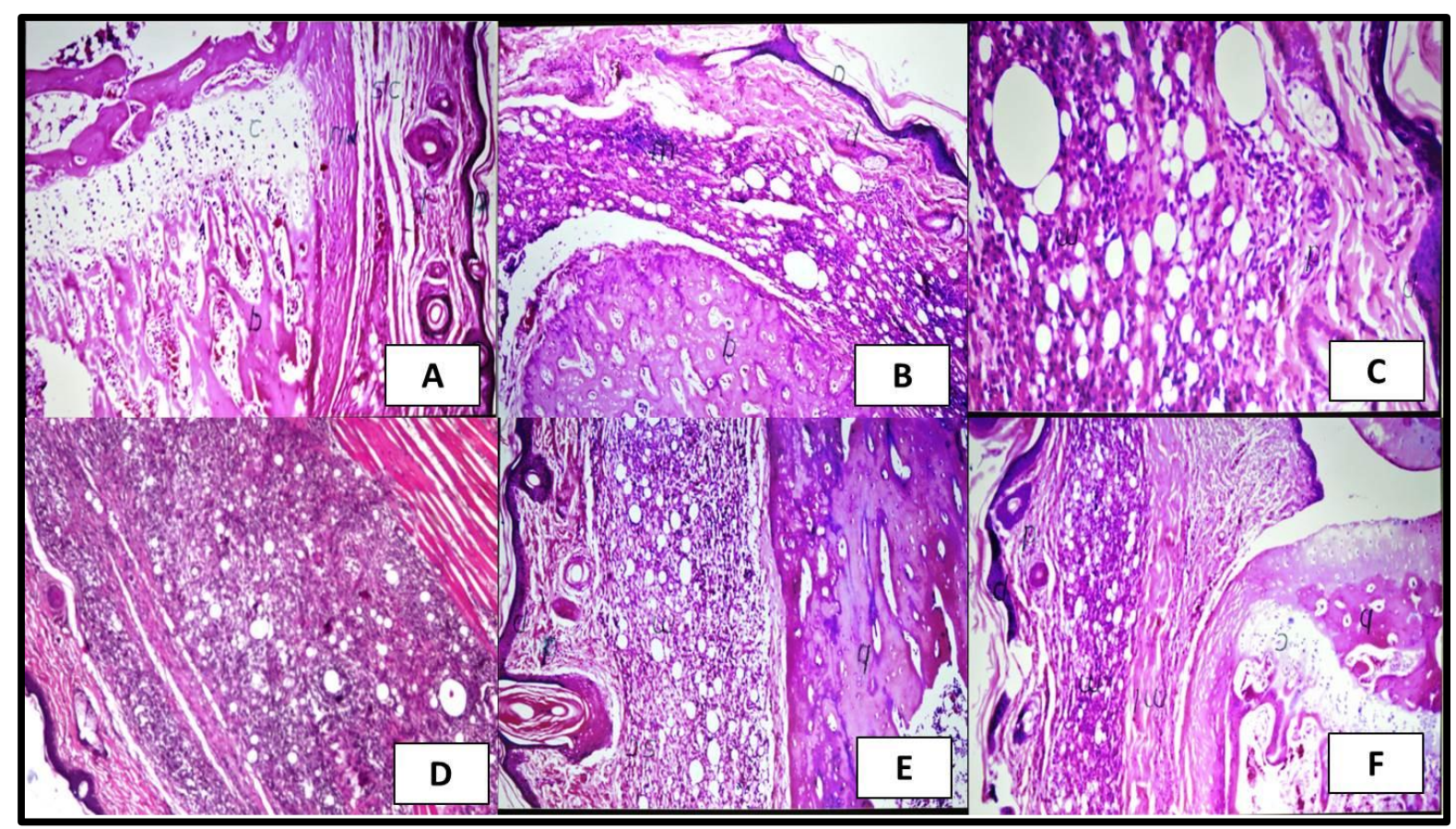

Fig.(3): photomicrographs of hind paw sections stained by $\mathrm{H} \& \mathrm{E}(\mathrm{x} 400)$.

A: paw section from normal rat shows normal histopathological appearance of subcutaneous tissue (sc), cartilage (c), and bone (b). B and C: paw sections from arthritic non-treated rat shows extensive inflammation in the dermal tissue (d), musculature $(\mathrm{m})$, and periarticular tissue. D: paw section from arthritic rat treated with res $12.5 \mathrm{mg} / \mathrm{kg}$ shows massive inflammation and fibrosis in the subcutaneous tissue that extends to the musculature. E: paw section from arthritic rat treated with res $25 \mathrm{mg} / \mathrm{kg}$ shows the inflammatory reaction in the subcutaneous tissue and extended to the periarticular tissue. F: paw section from arthritic rat treated with res $50 \mathrm{mg} / \mathrm{kg}$ shows The inflammatory cells infiltration localized in the subcutaneous tissue. 
Table 1 . Histopathological grading.

\begin{tabular}{|c|c|c|c|}
\hline \multirow[b]{2}{*}{ Groups } & \multicolumn{3}{|c|}{ Histopathological Alteration } \\
\hline & $\begin{array}{l}\text { Subcutaneous } \\
\text { inflammation }\end{array}$ & $\begin{array}{l}\text { Peri-articular } \\
\text { inflammation }\end{array}$ & Cartilage dystrophy \\
\hline Control & - & - & - \\
\hline $\begin{array}{c}\text { Arthritic non } \\
\text { treated }\end{array}$ & +++ & +++ & +++ \\
\hline $\begin{array}{l}\text { Resveratrol } \\
(12.5 \mathrm{mg} / \mathrm{kg})\end{array}$ & ++ & ++ & ++ \\
\hline $\begin{array}{l}\text { Resveratrol } \\
(25 \mathrm{mg} / \mathrm{kg})\end{array}$ & ++ & ++ & + \\
\hline $\begin{array}{l}\text { Resveratrol } \\
(50 \mathrm{mg} / \mathrm{kg})\end{array}$ & + & - & - \\
\hline
\end{tabular}

+++ (Severe), ++ (Moderate), + (Mild), - (Nil)

\section{REFERENCES}

Asquith, D L., Miller A M., McInnes L B., and Liew F Y. 2009. “Animal Models of Rheumatoid Arthritis.” European Journal of Immunology 39(8): 2040-2044. http://www.ncbi.nlm.nih.gov/pubmed/19672892 (February 28, 2017).

Benslay, D N, and Bendele A M. 1991. "Development of a Rapid Screen for Detecting and Differentiating Immunomodulatory vs. Anti-Inflammatory Compounds in Rats." Agents and actions 34(1-2): 254-256.

http://www.ncbi.nlm.nih.gov/pubmed/1793040 (December 9, 2016).

Bush, K A, Kirkham B W, and Walker J S. 2001. "The Kappa-Opioid Agonist, Asimadoline, Alters Cytokine Gene Expression in Adjuvant Arthritis." Rheumatology (Oxford, England) 40(9): 1013-1021. http://www.ncbi.nlm.nih.gov/pubmed/11561112 (December 24, 2016).

Carlson, R P et al. 1985. "Comparison of Inflammatory Changes in Established Type II Collagen- and Adjuvant-Induced Arthritis Using Outbred Wistar Rats." International journal of immunopharmacology 7(6): 811-826. http://www.ncbi.nlm.nih.gov/pubmed/4077344 (December 9, 2016).

Chen, H et al. 2016. "The Effect of Resveratrol on the Recurrent Attacks of Gouty Arthritis." Clinical Rheumatology 35(5): 1189-1195. http://www.ncbi.nlm.nih.gov/pubmed/25451618 (December 9, 2016).

Chen, X-Y et al. 2013. "Regulation of Synoviocyte Activity by Resveratrol in Rats with Adjuvant Arthritis." Experimental and therapeutic medicine 6(1): 172176. http://www.ncbi.nlm.nih.gov/pubmed/23935741 (December 24, 2016). 
Chen, $X$ et al. 2014. "Anti-inflammatory Effect of Resveratrol on Adjuvant Arthritis Rats with Abnormal Immunological Function via the Reduction of cyclooxygenase-2 and Prostaglandin E2." Molecular Medicine Reports 9:2592-2598. http://www.spandidospublications.com/10.3892/mmr.2014.2070 (March 3, 2017).

Cojocaru, M et al. 2010. "Extra-Articular Manifestations in Rheumatoid Arthritis." Maedica 5(4): 286-291. http://www.ncbi.nlm.nih.gov/pubmed/21977172 (February 28, 2017).

Darwish, S F. et al. 2013. "Targeting TNF- $\alpha$ and NF- $\kappa B$ Activation by Bee Venom: Role in Suppressing Adjuvant Induced Arthritis and Methotrexate Hepatotoxicity in Rats” ed. Hossam M. Ashour. PLoS ONE 8(11): e79284. http://dx.plos.org/10.1371/journal.pone.0079284 (December 24, 2016).

EImali, N. et al. 2007. "Effects of Resveratrol in Inflammatory Arthritis." Inflammation 30(1-2): 1-6. http://www.ncbi.nlm.nih.gov/pubmed/17115116 (December 9, 2016).

Gabriel, S E, and Michaud K. 2009. "Epidemiological Studies in Incidence, Prevalence, Mortality, and Comorbidity of the Rheumatic Diseases." Arthritis Research \& Therapy 11(3): 229. http://www.ncbi.nlm.nih.gov/pubmed/19519924 (December 6, 2016).

Gao, $X$ et al. 2001. "Immunomodulatory Activity of Resveratrol: Suppression of Lymphocyte Proliferation, Development of Cell-Mediated Cytotoxicity, and Cytokine Production.” Biochemical pharmacology 62(9): 1299-1308. http://www.ncbi.nlm.nih.gov/pubmed/11705464 (March 3, 2017).

Helyes, $\mathbf{Z}$ et al. 2001. "Anti-Inflammatory Effect of Synthetic Somatostatin Analogues in the Rat." British journal of pharmacology 134(7): 1571-1579. http://www.ncbi.nlm.nih.gov/pubmed/11724765 (December 24, 2016).

Ishikawa, $\mathbf{T}$ et al. 2009. "Prevention of Progressive Joint Destruction in CollagenInduced Arthritis in Rats by a Novel Matrix Metalloproteinase Inhibitor, FR255031." British Journal of Pharmacology 144(1): 133-143. http://www.ncbi.nlm.nih.gov/pubmed/15644877 (December 24, 2016).

Kim, K W et al. 2008. "Suppressive Effects of Bee Venom on the Immune Responses in Collagen-Induced Arthritis in Rats." Phytomedicine 15(12): 1099-1107. http://www.ncbi.nlm.nih.gov/pubmed/18424106 (December 24, 2016).

Kvien, T K. 2004. "Epidemiology and Burden of Illness of Rheumatoid Arthritis." PharmacoEconomics 22(Supplement 1): 1-12. http://link.springer.com/10.2165/00019053-200422001-00002 (February 28, 2017).

Leong, D J et al. 2013. "Nutraceuticals: Potential for Chondroprotection and Molecular Targeting of Osteoarthritis." International journal of molecular sciences 14(11): 23063-23085. http://www.ncbi.nlm.nih.gov/pubmed/24284399 (March 3, 2017).

Morović-Vergles, J. 2003. "Etiology of RA.” Reumatizam 50(2): 15-17. http://www.ncbi.nlm.nih.gov/pubmed/15098367 (December 9, 2016). 
Müller-Ladner, U et al. 2005. "Mechanisms of Disease: The Molecular and Cellular Basis of Joint Destruction in Rheumatoid Arthritis." Nature Clinical Practice Rheumatology 1(2): 102-110.

http://www.ncbi.nlm.nih.gov/pubmed/16932639 (December 6, 2016).

Park, S J et al. 2012. "Resveratrol Ameliorates Aging-Related Metabolic Phenotypes by Inhibiting cAMP Phosphodiesterases." Cell 148(3): 421-433. http://www.ncbi.nlm.nih.gov/pubmed/22304913 (December 9, 2016).

PEARSON, C M. 1956. "Development of Arthritis, Periarthritis and Periostitis in Rats given Adjuvants." Proceedings of the Society for Experimental Biology and Medicine. Society for Experimental Biology and Medicine (New York, N.Y.) 91(1): 95-101. http://www.ncbi.nlm.nih.gov/pubmed/13297719 (December 9, 2016).

Plasqui, G. 2008. "The Role of Physical Activity in Rheumatoid Arthritis." Physiology \& Behavior 94(2): 270-275. http://www.ncbi.nlm.nih.gov/pubmed/18234247 (December 6, 2016).

Ramprasath, V R, Shanthi P, and Sachdanandam P. 2006. "Therapeutic Effects of Semecarpus Anacardium Linn. Nut Milk Extract on the Changes Associated with Collagen and Glycosaminoglycan Metabolism in Adjuvant Arthritic Wistar Rats." Chemico-Biological Interactions 162(1): 43-52. http://www.ncbi.nlm.nih.gov/pubmed/16797506 (December 24, 2016).

Riveiro-Naveira, R. et al. 2016. "Resveratrol Lowers Synovial Hyperplasia, Inflammatory Markers and Oxidative Damage in an Acute Antigen-Induced Arthritis Model." Rheumatology 55(10): 1889-1900. http://www.ncbi.nlm.nih.gov/pubmed/27354682 (December 9, 2016).

Rovenský, J et al. 2009. "Treatment of Rat Adjuvant Arthritis with Flavonoid (Detralex $\left.{ }^{\circledR}\right)$, Methotrexate, and Their Combination." Annals of the New York Academy of Sciences 1173(1): 798-804. http://www.ncbi.nlm.nih.gov/pubmed/19758231 (December 24, 2016).

Singh, J A. et al. 2012. "2012 Update of the 2008 American College of Rheumatology Recommendations for the Use of Disease-Modifying Antirheumatic Drugs and Biologic Agents in the Treatment of Rheumatoid Arthritis." Arthritis Care \& Research 64(5): 625-639.

http://www.ncbi.nlm.nih.gov/pubmed/22473917 (December 9, 2016).

Tian, J et al. 2013. "Resveratrol Inhibits TNF- $\alpha$-Induced IL-1 $\beta$, MMP-3 Production in Human Rheumatoid Arthritis Fibroblast-like Synoviocytes via Modulation of PI3kinase/Akt Pathway.” Rheumatology International 33(7): 1829-1835. http://www.ncbi.nlm.nih.gov/pubmed/23328930 (December 9, 2016).

Trentham, D E, McCune W J, Susman P, and David J R. 1980. "Autoimmunity to Collagen in Adjuvant Arthritis of Rats." The Journal of clinical investigation 66(5): 1109-1117. http://www.jci.org/articles/view/109940 (December 6, 2016).

Tuncel, J et al. 2016. "Animal Models of Rheumatoid Arthritis (I): Pristane-Induced Arthritis in the Rat" ed. Hua Zhou. PLOS ONE 11(5): e0155936. http://www.ncbi.nlm.nih.gov/pubmed/27227821 (March 3, 2017). 
Valcarcel-Ares, M. N. et al. 2014. "Mitochondrial Dysfunction Promotes and Aggravates the Inflammatory Response in Normal Human Synoviocytes." Rheumatology 53(7): 1332-1343.

http://www.ncbi.nlm.nih.gov/pubmed/24609059 (December 9, 2016).

van Eden, W et al. 1989. "A Cartilage-Mimicking T-Cell Epitope on a $65 \mathrm{~K}$ Mycobacterial Heat-Shock Protein: Adjuvant Arthritis as a Model for Human Rheumatoid Arthritis." Current topics in microbiology and immunology 145: 27-43. http://www.ncbi.nlm.nih.gov/pubmed/2680295 (March 3, 2017).

van Eden, $\mathbf{W}$ et al. 1988. "Cloning of the Mycobacterial Epitope Recognized by $\mathrm{T}$ Lymphocytes in Adjuvant Arthritis." Nature 331(6152): 171-73. http://www.ncbi.nlm.nih.gov/pubmed/2448638 (March 3, 2017).

van Eden, W. Wagenaar-Hilbers J P, and Wauben M H. 2001. “Adjuvant Arthritis in the Rat." In Current Protocols in Immunology, Hoboken, NJ, USA: John Wiley \& Sons, Inc., Unit 15.4. http://www.ncbi.nlm.nih.gov/pubmed/18432736 (March 3, 2017).

Vivar, N, and Van Vollenhoven R F. 2014. "Advances in the Treatment of Rheumatoid Arthritis." F1000prime reports 6: 31. http://www.ncbi.nlm.nih.gov/pubmed/24860653 (December 9, 2016).

Xuzhu, G et al. 2012. "Resveratrol Modulates Murine Collagen-Induced Arthritis by Inhibiting Th17 and B-Cell Function." Annals of the Rheumatic Diseases 71(1): 129-135. http://www.ncbi.nlm.nih.gov/pubmed/21953348 (December $9,2016)$. 


\section{تأثير الكبد الوقائي لعقار "فورسكولين" في نموذج تجريبي لإصابة الكبد الحادة الناجمة عن رابع كلوريد الكربون}

\section{لل السادة الاكاترة}

نيرمين العجرودي' ريم أبو النجا'، رانيا شفيق ، ابتهال الدمرداش'

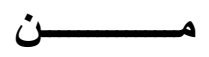

كلبة الصيلة، قسم الأوية والسموم، جامعة عين شعس، القاهرة، مصر

بكلبة الصيدلة، قسم الكبيباء الحيوية، جامعة عبن شهس، القاهرة، مصر

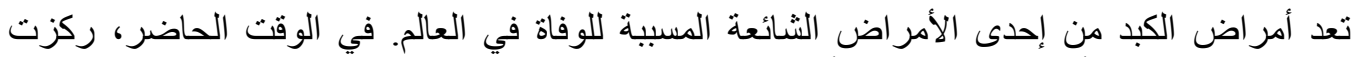

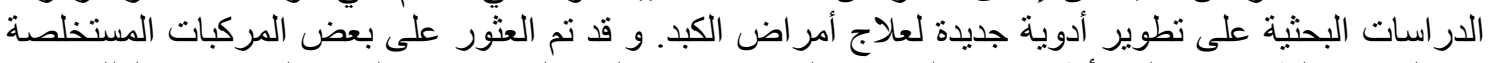

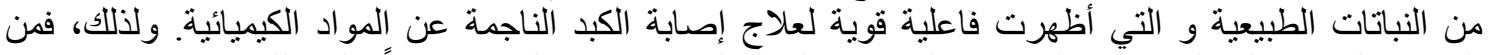

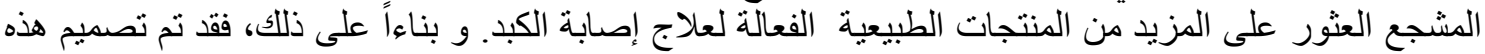

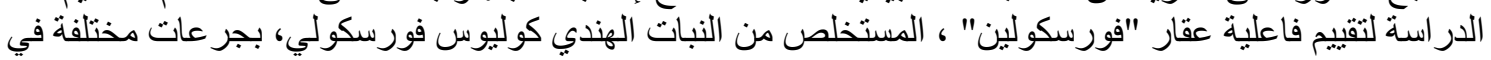

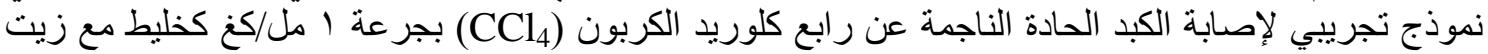

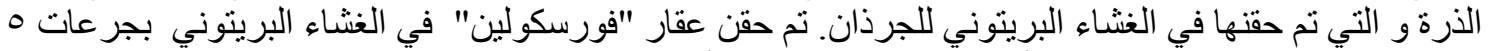

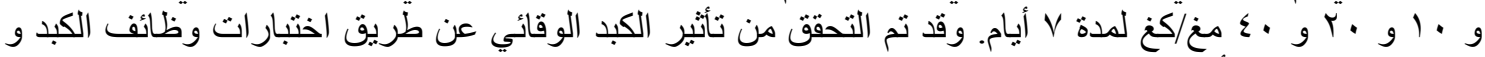

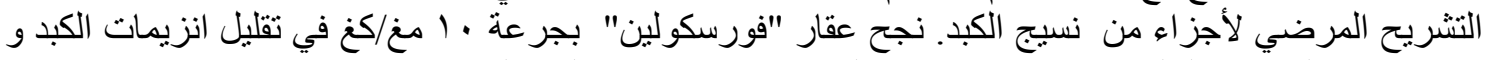

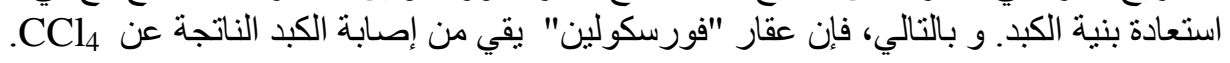

